\title{
Blois, Rocade nord
}

n064399

\section{Thibaud Guiot}

\section{(2) OpenEdition \\ Journals}

Édition électronique

URL : http://journals.openedition.org/adlfi/13811

ISSN : 2114-0502

Éditeur

Ministère de la culture

Référence électronique

Thibaud Guiot, «Blois, Rocade nord», ADLFI. Archéologie de la France - Informations [En ligne], Centre, mis en ligne le 29 octobre 2014, consulté le 19 avril 2019. URL : http://journals.openedition.org/ adlfi/13811

Ce document a été généré automatiquement le 19 avril 2019

(c) Ministère de la Culture et de la Communication, CNRS 


\section{Blois, Rocade nord}

$n^{\circ} 064399$

\section{Thibaud Guiot}

Lien Atlas (MCC) : http://atlas.patrimoines.culture.fr/atlas/trunk/index.php?

ap_theme=DOM_2.01.02\&ap_bbox=1.254;47.542;1.356;47.621

1 Cette opération d'évaluation a été réalisée dans le cadre du projet de construction de la Rocade nord de Blois, qui permettra la liaison entre le péage de l'autoroute A10 et la route de Vendôme. Le tracé de cette future route ( $2 \times 2$ voies) s'étend sur $2,3 \mathrm{~km}$. Les sondages systématiques ont permis de mettre au jour deux sites antiques, l'un sur la commune de Blois, au lieu-dit les Guignères, l'autre sur celle de Villebarou, au lieu-dit les Mardeaux.

2 L'extension de décapage au lieu-dit les Guignères a révélé un nombre important d'indices (structures excavées, empierrement et mobilier) qui attestent une occupation de cet espace, sous la forme d'un habitat, entre les $\mathrm{I}^{\text {er }}$ et $\mathrm{IV}^{\mathrm{e}} \mathrm{s}$., les éléments datants des $\mathrm{II}^{\mathrm{e}}-\mathrm{III}{ }^{\mathrm{e}} \mathrm{S}$ étant toutefois les plus nombreux.

3 Au lieu-dit les Mardeaux, ce sont des structures maçonnées, associées à des niveaux ayant livré du mobilier du $\mathrm{I}^{\mathrm{er}} \mathrm{s}$. apr. J.-C., qui indiquent la présence d'un établissement antique, dont la fonction reste toutefois indéterminée. Il s'agit de deux enclos de plan quadrangulaire de 21 mètres de côté, alignés selon un axe sud-ouest/nord-est et séparés de $0,75 \mathrm{~m}$. Le premier conserve encore, par endroits, la première assise de l'élévation; à l'intérieur, 3 murs aménagés contre la façade est et en son milieu forment un carré de $2,50 \mathrm{~m}$ de côté (intérieur). Le second enclos, dont la maçonnerie semble avoir été en grande partie récupérée, présente à l'intérieur 2 aménagements carrés de 2,75 $\mathrm{m}$ de côté (intérieur) dans les angles nord-est et sud-est. 
INDEX

Index géographique : Centre, Loir-et-Cher (41), Blois operation Sondage (SD)

Index chronologique : Gallo-romain

Mots-clés : habitat, enclos 